\title{
Labeling Preschoolers as Learning Disabled: A Cautionary Position
}

\author{
Kathryn A. Haring and David L. Lovett, University of \\ Oklahoma, Kay F. Haney and Bob Algozzine, University of \\ North Carolina at Charlotte, and Deborah D. Smith and \\ Jane Clarke, University of New Mexico
}

\begin{abstract}
The purpose of this article is to explore the issues concerning the adaptation of school-based service delivery concepts for use in early childhood special education programs. The use of categorical labels for determining eligibility for preschool children is not required by law-and may be detrimental. The following concerns are discussed: (a) definitional issues in learning disabilities versus low achievement, (b) the dangers of labeling and low expectation sets, (c) repeated failure to demonstrate movement through a continuum of services (particularly to least restrictive environments), and (d) the efficacy of early intervention and school-based special services for those with mild or suspected developmental disabilities. Research is reviewed concerning definitional and assessment issues utilizing learning disabilities as a construct. Alternatives for describing the characteristics of young children who are significantly at risk or developmentally delayed are provided.
\end{abstract}

Currently, the opportunity exists to establish high-quality services for young children with disabilities and to set the stage for future progress. It is imperative that early childhood professionals consider the ramifications of current service structures as well as of models proposed for the future. Those who have been instrumental in the development of services and service delivery systems for young children with disabilities should be commended, because much progress has been made in recent years. For example, the recognition of the importance of family involvement has helped to improve services and has influenced 
the focus of service provision beyond early childhood. Nevertheless, given the dynamic nature of service systems, there is room for new models that will lead to improved programs. However, we must be cautious in the application to early childhood services of old or reworked paradigms that were constructed to address services for older children. Our purpose here is to examine the issues surrounding the application of the learning disability construct to preschool children.

Given the persuasive positions taken in favor of early identification, assessment, and intervention for preschool children assumed to have learning disabilities (LD) (Esterly \& Griffin, 1987; Gemma, 1988; Kirk, 1987; Lerner, Mardell-Czudnowski, \& Goldenberg, 1987; McCarthy, 1989; Mercer, 1987; National Joint Committee on Learning Disabilities, 1986), one is hesitant to postulate a less optimistic (or alternative) paradigm. The field of learning disabilities, although traditionally fraught with inter- and intraorganizational conflict, appears to agree that adequate psychometric tools exist for isolating specific learning disabilities reliably, with predictive as well as social validity, in children from birth to 6 years of age. This position, well articulated by the National Joint Committee on Learning Disabilities (NJCLD), summarizes a consensus formed by such diverse groups in the LD community as the Council for Learning Disabilities, Division for Learning Disabilities of the Council for Exceptional Children, American Speech-Language-Hearing Association, Association for Children and Adults with Learning Disabilities, International Reading Association, The Orton Dyslexia Society, and the Division for Children with Communication Disorders of the Council for Exceptional Children. Briefly, their position is grounded in the special education traditions of intensive diagnostics, deficit-based interdisciplinary intervention, a continuum of program/service options, family involvement, systematic personnel preparation, and further research. One is tempted to conclude that the learning disabilities community proposes that the fundamental tenets of school-based special education services can be uncritically adapted to meet the needs of preschool children.

The NJCLD (1986) position paper recognizes the often discontinuous nature of early childhood development:

Normal development is characterized by broad ranges of individual and group differences, as well as by variability in rates and patterns of maturation. During the preschool years, this variability is marked. For some children marked discrepancies in abilities are temporary and are resolved 
during the course of development and within the context of experiential interaction. For other children, marked discrepancies persist within and among one or more domains of function, necessitating referral for systematic assessment and appropriate intervention. (NJCLD, 1986, p. 158)

However, the remainder of the paper reflects a limited perspective of early childhood special education. It also fails to address some of the limitations identified regarding the efficacy of the models of special education service provision for school-age children (Dunn, 1968; Reynolds, Wang, \& Walberg, 1987; Stainback \& Stainback, 1984; Wang \& Walberg, 1988).

It might be unreasonable to expect a position paper to reflect the enormity of historical perspective as well as current trends and issues in the field of special education. However, it is problematic to overlook the implications of concerns such as (a) definitional issues in learning disabilities versus low achievement, (b) the dangers of labeling and low expectation sets, (c) repeated failure to demonstrate movement through a continuum of services (particularly to least restrictive environments), and (d) the efficacy of early intervention and school-based special services for those with mild or suspected developmental disabilities. Addressing these factors is especially important when we consider the increasing numbers of children born into at-risk environments or who are substance-exposed. All of these factors must be viewed in the context of demographic changes in family systems and the increasing cultural diversity of American society. These concerns make the reliable identification of young children as having learning disabilities particularly problematic.

The purpose of this article is to explore the issues listed above and to discuss emergent models of early intervention service delivery. We are not saying that a substantial knowledge base concerning efficacious practices for school-based learning disabilities is absent, or that these practices have no implications for early intervention. We are saying that it is premature to endorse the adaptation of schoolbased service delivery models for early childhood special education. The dangers inherent in establishing separate structures for providing early childhood special education services to preschool children with mild developmental discrepancies must be considered.

Mounting evidence suggests that children who demonstrate severe academic difficulties during their school years tend to have pervasive problems throughout their lives. Early in the history of the LD field, 
professionals viewed learning disabilities as a childhood disability. The five federally funded research institutes of the late seventies and early eighties were designated to conduct research on children with LD. In addition, Kirk and Chalfant (1984) postulated that learning disabilities are developmental in nature. However, extensive data from follow-up studies of special education graduates with learning disabilities indicate that this disability is not strictly an academic condition unrelated to adult adjustment (Edgar, 1987; Haring, Lovett, \& Smith, 1990; Hasazi, Gordon, \& Roe, 1985; Mithaug, Horiuchi, \& Fanning, 1985). Unfortunately, longitudinal studies exploring later adult adjustment are not available yet. Is the concept of learning disabilities actually applicable to pre- and post-school-age services? Is it possible to overapply the concept?

\section{Definitional Issues}

From its inception in 1963, the term learning disabilities has been associated with poor academic performance. We have learned since then that school indicators of this disability extend beyond childhood and continue to manifest themselves throughout many of these individuals' adulthood. In other words, for many, learning disabilities is a lifelong disability (Mercer, 1987), with persistent features requiring compensatory actions. The identification of learning disabilities typically occurs during a student's elementary-school years-often around third grade, when reading abilities begin to take on more and more importance (Smith \& Luckasson, 1992). Along with the relatively new focus on early childhood education comes an interest in identifying these children while they are preschoolers.

The Individuals with Disabilities Education Act (IDEA), particularly under Public Law 99-457 (specifically Part H), requires states to identify and provide services to young children who have disabilities, an established risk, or developmental delays (Kochanek, Kabacoff, \& Lipsitt, 1990). Defining and operationalizing concepts like at-risk and developmental delay is difficult, and the processes vary across states (Simeonsson, 1991). Categorizing young children as having learning disabilities further raises conceptual and methodological concerns. For example, the current accuracy and validity of identification procedures available for very young children is questionable. 
In addition, IDEA does not require states to use categorical labels for service eligibility or reporting purposes with children 5 years of age and younger. An awareness of the limitations of present assessment procedures, and of the inappropriateness of the IDEA categories as guidelines for differentiating the service needs of preschool children, has prompted many states to adopt noncategorical eligibility options (McLean, Smith, McCormick, Schakel, \& McEvoy, 1991; Strickland $\&$ Turnbull, 1990). McLean et al. clearly articulated the issues surrounding categorical labeling of preschool children; unfortunately, their solution proposed to establish yet another category, that of developmental delay. This category, endorsed by national leaders and policymakers, may be appropriate for describing young children with disabilities; however, once the use of developmental delay as a category is fully institutionalized, it may be as restrictive and unlikely to facilitate meaningful, individualized services as any existing categorical label.

Multiple ecological and environmental factors (e.g., stressful events, mental health, educational achievement level, mother-child interactions) are predictive of child competence, specifically cognitive performance (Sameroff, Seifer, Barocas, Zax, \& Greenspan, 1987). A combination of these risk factors influences cognitive development by affecting a child's self-regulatory skills (Sameroff et al., 1987). In addition, children whose language development is delayed often have poor cognitive abilities, which affects their reasoning and problemsolving skills. A strong relationship exists between poor language development and learning disabilities (Cantwell \& Baker, 1987; Wallach \& Butler, 1984), which clearly indicates that such children need to receive early intervention. Despite these correlations, a single assessment instrument or set of procedures that accurately defines preschoolers with learning disabilities remains elusive.

Rossetti (1991) cautioned that tests administered in early childhood have not been shown to be highly predictive of later performance. Furthermore, young, at-risk children typically present a complex developmental profile that requires the careful interpretation of assessment results (Kennedy, Sheridan, Radlinski, \& Beeghly, 1991). Precisely diagnosing learning disabilities for very young children may not be possible at this time, but that should not prevent children from receiving services.

One hope of early intervention programs is that cases of learning disabilities might be prevented in the future. However, developing precise guidelines for prevention is impossible because we cannot pinpoint exact causes of this disability. Learning disabilities are often asso- 
ciated with central nervous system dysfunctioning (Hooper \& Willis, 1989 ), but, presently, this association does not lead to the exact selection of intervention strategies (not even in cases when a localized lesion has been identified). In addition, the plasticity of the nervous systems of very young children can result in recovery from known insults that would permanently disable an adult (Brazelton \& Cramer, 1990).

Early intervention programs can be critical to the futures of children at risk for learning or developmental disabilities. Programs such as Head Start and other well-structured preschool programs positively influence children's language and thinking skills (Casto \& Mastropieri, 1986) and their later success in school (Lazar, Hubbell, Murray, Rosche, \& Royce, 1977) without labeling them as having a disability or a learning disability. There is a need for young children at risk for or having disabilities to receive services, as well as a need for researchers to wrestle with important issues relating to diagnosis and intervention.

The field of learning disabilities has been continually burdened with debates over issues such as definition, causation, diagnostic criteria, intervention strategies, and service delivery options. The bases for such disagreements rest in the lack of theoretical underpinnings and the lack of replication and generalizability of the massive body of research findings (Hammill, Bryant, Brown, Dunn, \& Marten, 1989). For example, major diagnostic difficulties have been associated with the use of specific discrepancy formulas inherent in nearly all definitions of this disability (Hooper \& Willis, 1989).

Nationally, large numbers of students tend to be identified as having learning disabilities without adherence to stringent criteria, and the result is an ever-growing category of exceptional learners (Smith \& Luckasson, 1992). Clearly, the category of learning disabilities comprises a heterogeneous population of learners, but special education cannot and should not serve every student who demonstrates academic achievement somewhat below the expected average range.

The development of a replicated research base for early intervention is imperative, just as it is for the entire field of learning disabilities (Wolery, 1991). Over the years, concern about the identification of subjects for learning disabilities research has received national attention (Hammill et al, 1989; Smith et al., 1984). Merely identifying subjects as either "at risk" or "school identified learning disabled" is insufficient for consumers of research findings.

What, then, is the solution? Smith et al. proposed that researchers studying school-age youngsters with learning disabilities provide a detailed set of demographic information in every research report 
about this group of students. A comparable solution also has merit for preschoolers. We suggest that all researchers studying young children carefully describe their subjects. One way to have consistency across research studies is for every published experiment to include the same demographic data. This is consistent with previous recommendations suggesting that a common set of marker variables, or reference points, be used in describing and identifying subjects with learning disabilities (Keogh, 1987a, 1987b). To that end, we developed the descriptor table (see Figure 1) for early childhood specialists to use in the subjects section of research reports.

\section{Clusters of Characteristics}

In lieu of labeling preschoolers as having learning disabilities, we advocate identifying clusters of characteristics that might indicate a student is at risk for later academic difficulty. Those characteristics are as follows: (a) lack of concept development; (b) speech delays; (c) receptive and expressive language delays; (d) directionality problems; (e) gross and fine motor delays; ( $f$ ) attentional problems; (g) hyperactivity; (h) immature reasoning abilities; (i) visual and/or auditory perceptual problems; (j) lack of academic readiness skills (i.e., alphabet knowledge, quantitative concepts, etc.); and (k) social and/or affective skills deficits (Lerner, 1988; Lovitt, 1989).

Knowing that problems may arise in one area or in a variety of these areas, teachers should pinpoint delays as possible red flags and give added support in identified areas of risk. However, it is not just students at risk for learning disabilities who exhibit problems in these areas. Many students who later function adequately in academic areas have also demonstrated deficits or lags at an earlier age. This supports the contention that these students can be best served by welltrained early educators and be adequately served without receiving a label at such an early and vulnerable age. Identifying students' strengths and weaknesses and addressing those areas in the context of an early childhood education program, rather than in a restrictive environment, may enable students to deal with developmental delays or cope with developmental deficits in the mainstream of education.

Identifying children under age 6 as disabled is a process fraught with difficulty: Intelligence quotient (IQ) scores are known to be unstable in young children (Spitz, 1986); learning disabilities are based 
Name:

Gender:

Age:

Ethnicity:

Developmental Categories

Provide profile of the following: (Indicate test, inventory, observations, parental interview, etc.)

A. Cognitive Self-Regulatory Skills:

B. Communicative Competence: (language, speech, gestures)

C. Motoric Behaviors: (automatic, reflexive, gross, fine)

D. Social Adaptive Behaviors:

E. Acuity: Hearing and Vision

Concern Areas:

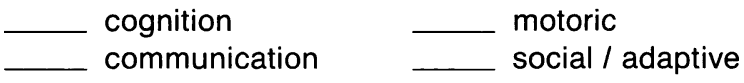

F. Other Pertinent Information:

Risk Categories (Tjossem, 1976):

+ Present $\quad X$ Not Present

A. Established

Chromosomal

Neurological

_ Metabolic

B. Biological

Alcohol Abuse

Drug Abuse

Birth Weight

(Continues)

Figure 1. Descriptor table for early childhood specialists. 
C. Environmental

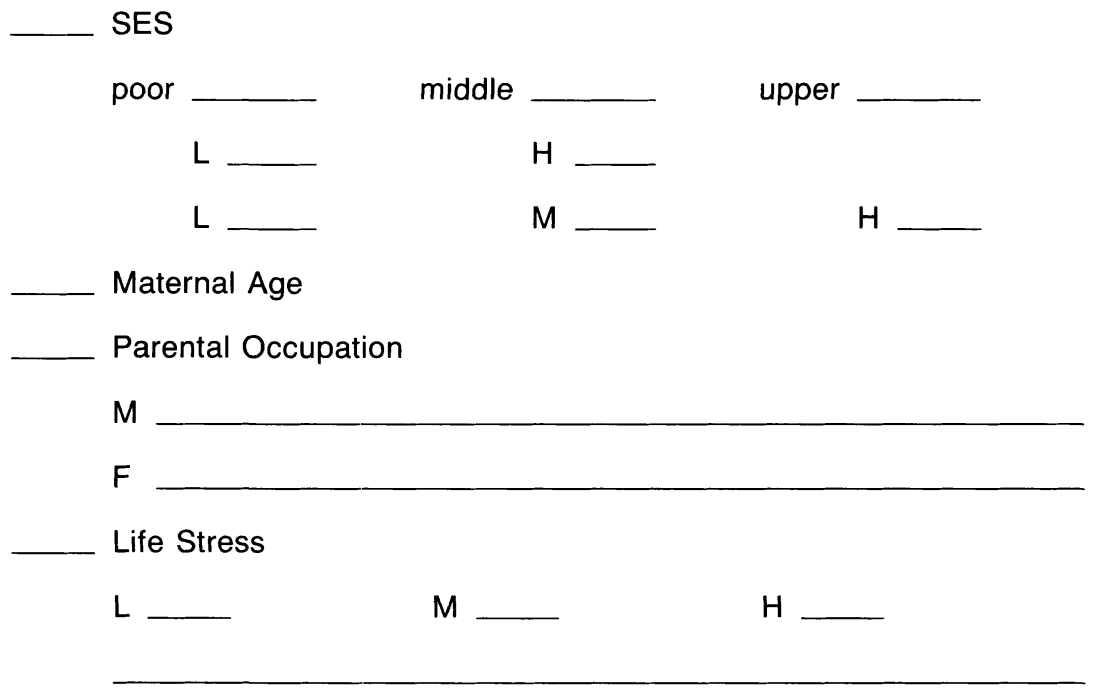

Parent / Child Interactive Behaviors

Number of Factors Present:

Established

Biological

Environmental

Figure 1. (Continued)

on academic delays that do not surface until school age. More than 4 million students received special education services during recent school years, with more than $40 \%$ of those students classified on the basis of "hidden handicaps" (which were not even recognized as being important when the earliest special education programs were established). In fact, recent government figures indicate that there are more students with learning disabilities receiving special education than any other group of exceptional students (U.S. Department of Education, 1990). Identification and classification practices for these students have been plagued by problems since learning disabilities first became part of special education's taxonomy. 


\section{Issues in Assessment of Learning Disabilities}

From inception, learning disabilities have been characterized by implied process disorders producing achievement problems. The search for critical links between process disorders and academic performance has been unproductive (Ysseldyke \& Algozzine, 1990). Research has consistently demonstrated that severity of academic delay is the only characteristic that differentiates students with and without LD (Ysseldyke, Algozzine, \& Thurlow, 1992). After 5 years of research, Ysseldyke and Algozzine (1984) concluded that no defensible system for classifying students with learning disabilities existed.

In work at the University of Minnesota, Institute for Research on Learning Disabilities, Ysseldyke and his colleagues examined the overlap among categorical groups in performance on psychometric measures, and the extent to which diagnostic personnel were able to differentiate clinically among special education groups. In one such investigation, more than 40 tests were administered to 49 students called learning disabled by their schools and to 50 low achieving students who scored below the 25 th percentile on a group-administered achievement test. Performances on intellectual, achievement, and perceptual-motor tests, on measures of classroom behavior, and on self-concept tests showed an average of $96 \%$ overlap between groups, making it very difficult psychometrically to differentiate between low achieving students and those labeled learning disabled (Ysseldyke, Algozzine, Shinn, \& McGue, 1982). In a follow-up study (Ysseldyke \& Algozzine, 1983), professionals were asked to review the scores of students with learning disabilities and low achieving students and to use their clinical judgment to identify those students who were, in their opinion, learning disabled. Using both school placement and the federal definition as criteria, professionals were correct about half the time. Both investigations provide evidence that professionals are currently unable to differentiate, either psychometrically or clinically, between low achieving students and those called learning disabled by school personnel. A summary of additional research illustrating problems associated with assessment and diagnosis of students with learning disabilities is provided in Table 1.

In an article in the Journal of Learning Disabilities addressing screening and diagnosis in a series on the future of the LD field, Algozzine and Ysseldyke (1986) summarized their research related to classification: 
While many school identified learning disabled students do meet commonly applied criteria (e.g., 15 point difference between ability and achievement, subtest scatter), some do not (Algozzine \& Ysseldyke, 1982). Many low-achieving students, never classified as LD, also meet these same criteria (Epps, Ysseldyke, \& Algozzine, 1983), and many normal students are classifiable using these criteria (Ysseldyke, Algozzine, \& Epps, 1983). In fact, the overlap in scores for many of these students is so great (Algozzine \& Ysseldyke, 1983; Ysseldyke \& Algozzine, 1982; Ysseldyke, Algozzine, Shinn, \& McGue, 1982) that it is difficult for them not to be classified when commonly used criteria are applied to performance estimates on commonly used assessment devices. (p. 396)

In addition, results of the research at the University of Kansas Institute for Research in Learning Disabilities indicated the difficulty in distinguishing between children with LD and those with other achievement-related problems (Schumaker, Deshler, Alley, \& Warner, 1980; Warner, Schumaker, Alley, \& Deshler, 1980). These researchers reported that the major difference between the LD and low achieving (LA) groups was in the degree of disability. The performance in reading, math, and written language by students with LD was significantly below that of the LA students at the junior and senior high school levels. The groups also differed on estimated ability at the senior high school level. The average intellectual ability score for the LD groups, however, was "substantially below" the norm of 100 . Based on their sample, the Kansas investigators suggested that "for many of the LD students, the traditional label of 'slow learner' would be more appropriate" (Warner et al., 1980, p. 31). In summary, the Kansas researchers found overlap between school-identified pupils with LD and LA pupils. Many students identified as having LD were characterized by generalized rather than specific learning deficits, which made it difficult to separate them from other low achieving students.

Recent attempts to redefine LD have done little to create diagnostic purity greater than that created by operationalizing the commonly used federal definition, and there is no reason to believe that problems associated with identifying students with learning disabilities will improve as efforts to provide services engage children at younger and younger ages. 


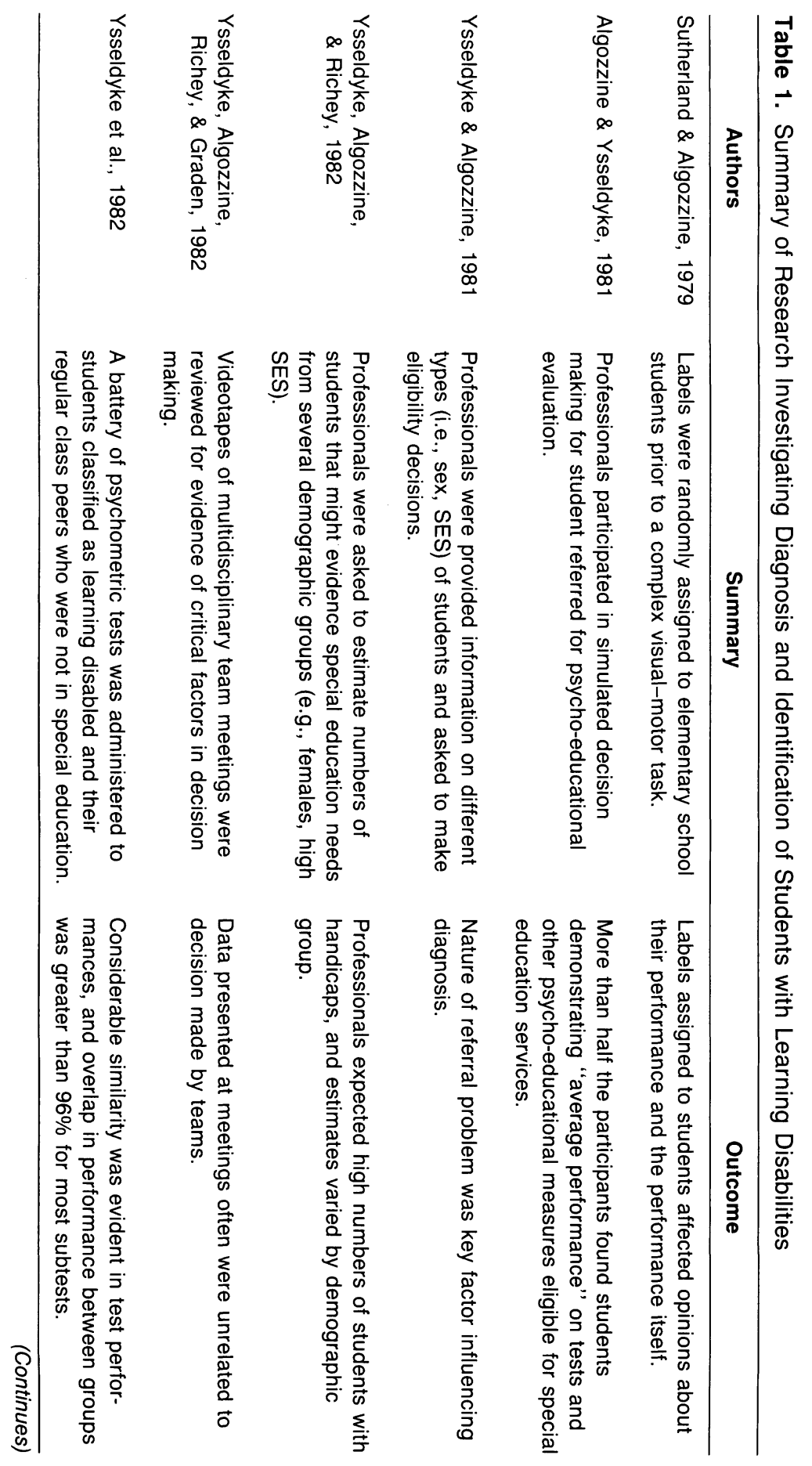




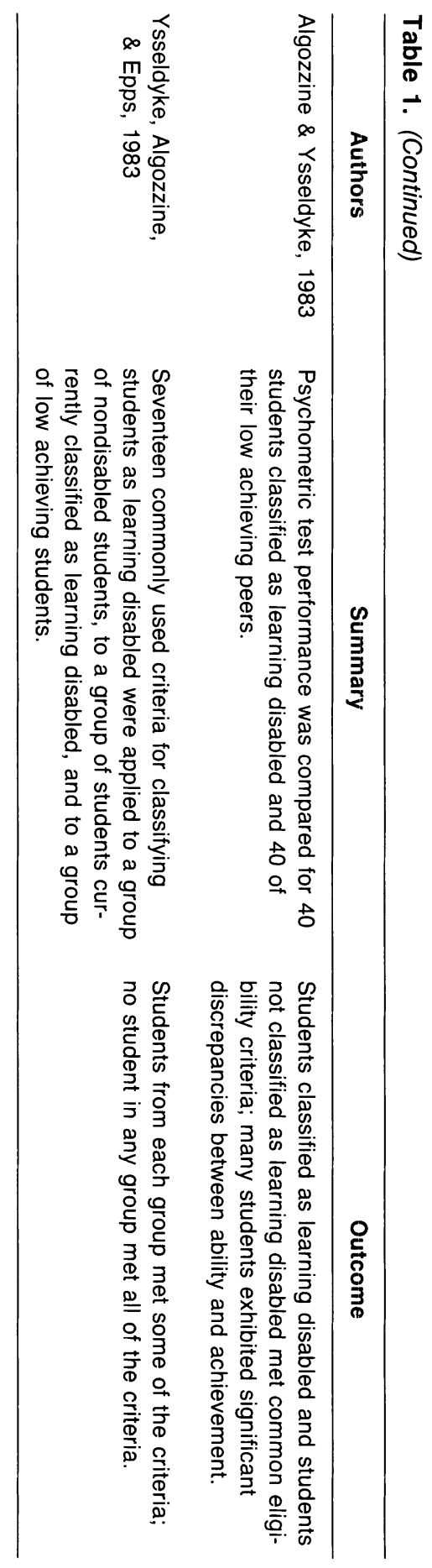




\section{Labeling and Low Expectation Set}

Labeling appears to serve both a positive and a negative purpose. On the positive side, it enhances the opportunity for funding for special groups of individuals and it seems to make it easier for professionals to communicate with one another (Ysseldyke \& Algozzine, 1990). On the negative side, labeling tends to lower the expectations of teachers who are delivering services to the special learner. In such instances, the student is less likely to be treated normally, his or her opportunity for normal schooling is reduced, and the main focus tends to be on the student's weaknesses instead of his or her strengths.

Teacher expectations can change the student-teacher relationship and lead to differential treatment because of preconceived ideas regarding students' ability (Rosenthal \& Jacobson, 1968). Student behaviors are driven, in part, by teacher expectations. Some teachers, parents, and other students think less of a student who carries the label of learning disability. If low expectations begin in early childhood and persist throughout the school years, students labeled learning disabled may never reach their true potential, because their best is never expected from them.

Although research on the effects of labeling is equivocal, exposing preschool students to possible detrimental effects seems unnecessary. A label can be a lasting stigma that, in many cases, follows students throughout their school careers. It behooves us, as professionals, to move forward very cautiously when considering labeling young preschoolers. An alternative route is strongly recommended (and one alternative proposal is presented later in this article).

When addressing the two major reasons for labeling studentsfunding and service delivery-it becomes apparent that funding for at-risk preschoolers is already in place, through P.L. 94-142 and P.L. 99-457. As for delivery of services, well-trained early childhood educators are prepared to teach students functioning at developmental levels ranging from birth to 6 years of age. Whether the student is developmentally on-target or developmentally delayed, these professionals can be prepared to provide appropriate services. Although the fit between guidelines for practices in early childhood settings and best practices in early childhood special education is not seamless, models of successful full inclusion of children with disabilities are emerging (Salisbury, 1991). Clearly, research is needed to validate full-inclusion models. As research emerges, the attitudinal, administrative, and logistical barriers separating services delivered to children on the basis 
of ability levels are breaking down (Thousand \& Villa, 1990). The role of special educators is to assure that the developmental potential of less abled children is enhanced. No child should be drowned in the sea of mediocrity that characterizes services to young children in general. The additional resources currently allocated to support children who are not developing normally are insufficient to make vast improvements in early childhood services. We can, however, select quality childcare/preschool settings designed for regular children and provide special service supports to maximize the development of children with disabilities within those environments. Therefore, it seems educationally unnecessary to label children in order for them to receive appropriate educational services.

Techniques employed in teaching students with learning disabilities have also proven effective when working with students in Chapter I programs, slow learners, and those in regular education (Lovitt, 1989). Research has shown that effective teaching methods (e.g., advanced organizers, test-taking strategies, direct instruction, Montessori methods, repeated readings, etc.) are generally good for more than one type of student and for students from widely varied socioeconomic backgrounds. Research also has demonstrated that modeling and active learning produce excellent results. Knowing this, it becomes more difficult to understand why knowledgeable professionals in special education continue to advocate (a) labeling at earlier and earlier ages; (b) isolating students with mild developmental delays from appropriate peer models; and (c) teaching students with mild developmental delays in an artificial environment, knowing that these students do not automatically generalize what has been learned to real-life environments. With the knowledge we have regarding generalization of learning, best practice seems to be to try and educate our youngest students in a realistic, active, and participatory environment with students from varying developmental levels.

In summary, there appears to be very little to gain and a great deal to lose from labeling a preschooler as having learning disabilities. Methodological practice should be determined through the identification of strengths and weaknesses, not by an arbitrary label.

\section{Continuum of Services}

The NJCLD 1986 position paper stated that a continuum of service and program options should be provided to preschoolers with 
learning disabilities. We concur that a range of service types, intensities, and settings should be available; however, there is a danger in providing a continuum of services sequentially ordered according to the magnitude of most to least restrictive environments. Problems involving a lack of movement through the continuum of services for school-age children and in adult services have been reported (Taylor, 1988). It appears that those placed in segregated services tend to remain there instead of gaining necessary skills toward independent functioning that would move them to more normalized settings. We suggest that a fluid array of services be arranged (Smith \& Luckasson, 1992). Although there is little argument that early intervention programs should be integrated (McDonnell \& Hardman, 1988; Strain, 1990; Wolery, 1991), there is evidence that this best practice is not standard practice. If a continuum of program and service options is to exist for preschoolers, the provision of segregated services should not be an option in that continuum.

\section{Components of Model Service Delivery}

There is widespread interest in what constitutes best or model practice in programs serving children under 6 years of age who have disabilities or who are at risk. Guidelines describing basic tenets to assure program quality are needed. Research to determine most effective practices has not historically preceded practice in this area (Westlake \& Kaiser, 1991). Indeed, certain model practices can be advocated for young children in the absence of solid research results. Wolery (1991), in a recent article, cited several characteristics formed by the general consensus of early intervention professionals. Most agree that services should be individualized, be based on child and family assessment, be culturally and linguistically sensitive, be designed to maximize child development and functioning, be integrated, and involve interdisciplinary collaboration. McDonnell and Hardman (1988) identified the six characteristics of an exemplary early intervention program: that it be (a) integrated, (b) comprehensive, (c) normalized, (d) adaptable, (e) peer- and family-referenced, and (f) outcome-based. They defined integration as grouping children with and without handicaps together for instructional or social activities. They further specified that service sites outside the family home be generic and that systematic contact with nonhandicapped children be arranged. Comprehensive 
programs included assessment, planning, instructional programming, service coordination and evaluation, a transdisciplinary approach, theoretically and procedurally well-defined models, and direct instruction. A normalized program supports the parents' role, is ageappropriate, promotes generalization, encourages self-initiation, and avoids artificial reinforcement or aversive techniques. Adaptable services are those that support a variety of family structures, are flexible and noncategorical, are individualized, and emphasize functionality of response as well as formative evaluations for programmatic changes. Peer- and family-referenced services tend to include parents as full partners, consider family routines when enhancing child skill development, and reference the curriculum to individual child, family, peer, and community concerns (McDonnell \& Hardman, 1988).

The consensus is developing in the early childhood special education community that services need to be provided to children in normalized, community-based sites (Hanson \& Haring, in press). Services should follow the child, so that the child is not "pulled out" or isolated from others for special services. The model proposed here requires special service providers from all disciplines to provide needed support or therapies to children in their homes, day care, or regular school settings. Clearly, more model demonstration research projects are needed to assist the field to meet individualized child needs in structures designed for groups of normally developing children. When special service providers are viewed as a supportive asset to regular staff members and care is taken to meet the individualized needs of identified children in a program, effective integrated services can be achieved.

\section{Efficacy of Early Intervention}

More than two decades of data seem to confirm the efficacy of early intervention (Meisels, 1985). In addition, federal legislation and policy have dictated that special education intervention begin as early as possible in the life cycle of identified individuals. However, discussions of the efficacy of early intervention continue (Bricker, Bailey $\&$ Bruder, 1984; Casto \& Mastropieri, 1986; Dunst, 1986; Dunst \& Rheingrover, 1981; Odom \& Fewell, 1983; Guralnick \& Bennett, 1987; Simeonsson, Cooper, \& Scheiner, 1982; White, Bush, \& Casto, 1985). In fact, national research institutes to study the efficacy of early intervention continue to be funded, for example, the Early Intervention 
Research Institute (EIRI) at Utah State University. Issues of participant selection/assignment, description of specific intervention strategies, and instrumentation continue to confound methodological purity, thereby limiting the generalizability of early intervention research. Recent nonsignificant results of EIRI studies (Lowitzer \& Haring, 1991; White, Toohill, \& Haring, 1991), which were designed to avoid the methodological limitation of earlier research, are in the process of being disseminated. The lack of significant effects between groups receiving the same interventions in varying degrees of intensity reported in these studies may again stimulate debate.

Unfortunately, until we have a consensus on what best practices in early intervention are (Hanson \& Haring, in press; McDonnell \& Hardman, 1988; Westlake \& Kaiser, 1991), we will continue to waste precious resources conducting research on mediocre early intervention programs, to produce equivocal results. Further, debate concerning the general efficacy of school-based special education for students with mild disabilities persists (Dunn, 1968; Edgar, 1987: Reynolds et al., 1987; Stainback \& Stainback, 1984; Wang \& Walberg, 1988), and it will continue whether or not significant improvements are made in methodologies utilized to study efficacy. We should not stop providing special services to those in need simply because we are not sure how effective those services are, just as we should not deny special services to very young children in need because we are justifiably hesitant to label them as disabled.

Providing special education within the public school structure has created a system of labeling students to assure that adequate resources are available to serve those in need. Students, therefore, have had to demonstrate a substantiated need (i.e., disability) to receive those special services. What we want to avoid in early intervention services is the tendency to apply the same structures to young children that are utilized (and may not have been beneficial) for school-age students. In preschool settings, where curricular goals for all children are similar (e.g., language, social, motor, cognitive, and self-help skills development), there is little rationale for applying labels that have not been shown to result in more effective services.

\section{Preschool Learning Disabilities in Perspective}

This article has posed the question, Is the concept of learning disabilities applicable to preschool services? In attempting to answer this 
question we have explored ways in which the definition and defense of the concept are controversial when applied to school-aged populations. This discussion alone suggests a cautious application of the learning disabilities construct to preschool children.

The school-based diagnosis of a learning disability has traditionally been determined with a formula specifying a significant discrepancy between potential and achievement. This determinant is inappropriate for children under 6 years of age, primarily because there are no standardized instruments with adequate predictive validity to establish any sense of potential achievement for children this age. One of the major difficulties in early intervention research has been this lack of adequate measurement of present ability and potential achievement. Diagnostic discrepancy formulas for school-age students commonly utilize an IQ score. It is well established that IQ is an unstable construct for many children, particularly those under 6 years of age (Spitz, 1986). What indices are we to employ to establish a discrepancy score for preschool children? We suggest that an empirical basis has been established concerning the biological and environmental factors that place a very young child at risk. Federal legislation and resulting policy endorse the use of an at-risk category to determine eligibility for special services. Unfortunately, resources for early intervention are limited and states are extremely hesitant to serve at-risk children. Nevertheless, the opportunity exists to provide services to young children in need without the possible disadvantages of labeling. Identifying preschoolers in need of special services does not require the use of specific labels. It does necessitate a dedication to providing appropriate services using the best available practices. When conducting research or disseminating findings about demonstration projects, we suggest that, whether labeled or not, subjects' demographic characteristics should be carefully described. Otherwise, replication of effective services and practices cannot be guaranteed, and our growing knowledge base will be severely limited.

\section{References}

Algozzine, B., \& Ysseldyke, J.E. (1981). Special education services for normal children: Better safe than sorry. Exceptional Children, 48 238-243.

Algozzine, B., \& Ysseldyke, J.E. (1982). Classification decisions in learning disabilities. Educational and Psychological Measurement, 2(2), 117-129.

Algozzine, B., \& Ysseldyke, J.E. (1983). Learning disabilities as a subset of school failure: The oversophistication of a concept. Exceptional Children, 50, 242-246. 
Algozzine, B., \& Ysseldyke, J.E. (1986). The future of the LD field: Screening and diagnosis. Journal of Learning Disabilities, 19, 394-398.

Brazelton, T.B., \& Cramer, B.G. (1990). The earliest relationship. Reading, MA: Addison-Wesley.

Bricker, D., Bailey, E., \& Bruder, M. (1984). The efficacy of early intervention and the handicapped infant: A wise or wasted resource? Advances in Developmental and Behavorial Pediatrics, 5, 373-423.

Cantwell, D.P., \& Baker, L. (1987). Developmental speech and language disorders. New York: Guilford Press.

Castro, G., \& Mastropieri, M.A. (1986). The efficacy of early intervention programs: A meta analysis. Exceptional Children, 52, 417-424.

Dunn, L.M. (1968). Special education for the mildly retarded-Is much of it justifiable? Exceptional Children, 35, 5-22.

Dunst, C.J. (1986). Overview of the efficacy of early intervention programs: Methodological and conceptual considerations. In L. Bickman \& D. Weatherford (Eds.), Evaluating early intervention programs for severely handicapped children and their families (pp. 79-148). Austin, TX: PRO-ED.

Dunst, C.J., \& Rheingrover, R.M. (1981). An analysis of the efficacy of early intervention programs with organically handicapped children. Evaluation and Program Planning, 4, 287-323.

Edgar, E. (1987). Secondary programs in special education: Are many of them justifiable? Exceptional Children, 53, 555-561.

Epps, S., Ysseldyke, J.E., \& Algozzine, B. (1983). Public policy implications of different definitions of learning disabilities. Journal of Psychoeducational Assessment, 1, 341-352.

Esterly, D.L., \& Griffin, H.C. (1987). Preschool programs for children with learning disabilities. Journal of Learning Disabilities, 20, 571-573.

Gemma, A. (1988). Early intervention for preschool children with learning disabilities. (EDRS 326032) Pub Type: Information Analyses.

Guralnick, M.J., \& Bennett, F.C. (1987). A framework for early intervention. In M.J. Guralnick \& F.C. Bennett (Eds.), The effectiveness of early intervention for at-risk and handicapped children (pp. 3-29). Orlando, FL: Academic Press.

Hammill, D., Bryant, B., Brown, L., Dunn, C., \& Marten, A. (1989). How replicable is current LD research? A follow-up to the CLD research committee's recommendations. Learning Disability Quarterly, 12, 174-179.

Hanson, M.J., \& Haring, K.A. (in press). Early intervention programs and integration. In K.A. Haring, D.L. Lovett, \& N.G. Haring (Eds.), Integrated life cycle services for persons with disabilities. New York: Springer-Verlag.

Haring, K.A., Lovett, D.L., \& Smith, D.D. (1990). A follow-up study of recent special education graduates of learning disabilities programs. Journal of Learning Disabilities, 23, 108-113.

Hasazi, S.B., Gordon, L.R., \& Roe, C.A. (1985). Factors associated with the employment status of handicapped youth exiting high school from 1979 to 1983. Exceptional Children, 51, 455-469.

Hooper, S.R., \& Willis, W.G. (1989). Learning disability subtyping: Neuropsychological foundations, conceptual models, and issues in clinical differentiation. New York: Springer-Verlag. 
Kennedy, M.D., Sheridan, M.K., Radlinski, S.H., \& Beeghly, M. (1991). Playlanguage relationships in young children with developmental delays: Implications for assessment. Journal of Speech and Hearing Research, 34, 112-122.

Keogh, B. (1987a). Learning disabilities: In defense of a construct. Learning Disabilities Research, 3(1), 4-9.

Keogh, B. (1987b). A shared attribute model of learning disabilities. In S. Vaughan \& C. Boss (Eds.), Research in learning disabilities (pp. 3-18). Austin, TX: PRO-ED.

Kirk, S.A. (1987). The learning disabled preschool child. Teaching Exceptional Children, 19(2), 78-80.

Kirk, S.A., \& Chalfant, J.C. (1984). Academic and developmental learning disabilities. Denver: Love.

Kochanek, T., Kabacoff, R., \& Lipsitt, L. (1990). Early identification of developmentally disabled and at-risk preschool children. Exceptional Children, 56, 528-538.

Lazar, I., Hubbell, V.R., Murray, H., Rosche, M., \& Royce, J. (1977). The persistence of preschool effects: A long term follow-up of fourteen infant and preschool experiments. Washington, DC: Office of Human Development Services, U.S. Department of Health, Education, and Welfare.

Lerner, J. (1988). Learning disabilities (5th ed.). Boston: Houghton Mifflin.

Lerner, J., Mardell-Czudnow'ski, C., \& Goldenberg, D. (1987). Special education for the early childhood years. Englewood Cliffs, NJ: Prentice-Hall.

Lovitt, T.C. (1989). Introduction to learning disabilities. Boston: Allyn \& Bacon.

Lowitzer, C.A., \& Haring, K.A. (1991). The efficacy of once per week versus twice per week home visits on child and family functioning. Manuscript submitted for publication.

McCarthy, J.M. (1989). Through my kaleidoscope-1989 elements from the past with promise for the future. Learning Disabilities Focus, 4(2), 67-83.

McDonnell, A., \& Hardman, M. (1988). A synthesis of "best practice" guidelines for early childhood services. Journal of the Division for Early Childhood, 12(4), 328-341.

McLean, M., Smith, B.J., McCormick, K., Schakel, J., \& McEvoy, M. (1991, May). Developmental delay: Establishing parameters for a preschool category of exceptionality. Reston, VA: Division for Early Childhood, Council for Exceptional Children.

Meisels, S.J. (1985). A functional analysis of the evolution of public policy for handicapped young children. Educational Evaluation and Policy Analysis, 7, 115-126.

Mercer, C.D. (1987). Students with learning disabilities (3rd ed.). Columbus, OH: Merrill.

Mithaug, D.E., Horiuchi, C.N., \& Fanning, P.N. (1985). A report on the Colorado statewide follow-up survey of special education students. Exceptional Children, 51, 397-404.

National Joint Committee on Learning Disabilities. (1986). Learning disabilities and the preschool child: A position paper of the National Joint Committee on Learning Disabilities. Learning Disability Quarterly, 9(2), 158-163.

Odom, S.L., \& Fewell, R.R. (1983). Program evaluation in early childhood special education: A meta-evaluation. Educational Evaluation and Program Analysis, 5, 443-460. 
Reynolds, M.C., Wang, M.C., \& Walberg, H.G. (1987). The necessary restructuring of special and regular education. Exceptional Children, 53, 391-398.

Rosenthal, R., \& Jacobson, L. (1968). Pygmalion in the classroom. New York: Holt, Rinehart \& Winston.

Rossetti, L. (1991). Infant toddler assessment: A clinical perspective. Infant Toddler Intervention, 1, 11-25.

Salisbury, C.L. (1991). Mainstreaming during the early childhood years. Exceptional Children, 58, 146-155.

Sameroff, A., Seifer, R., Barocas, R., Zax, M., \& Greenspan, S. (1987). Intelligence quotient scores of 4 year old children: Social environmental risk factors. Petiatrics, 79, 343-350.

Schumaker, J.B., Deshler, D.D., Alley, G.R., \& Warner, M.M. (1980). An epidemiological study of learning disabled adolescents in secondary schools: Details of the methodology (Research Rep. No. 12). Lawrence: The University of Kansas Institute for Research in Learning Disabilities.

Simeonsson, R. (1991). Early intervention eligibility: A prevention perspective. Infants and Young Children, 3, 48-55.

Simeonsson, R.J., Cooper, D.H., \& Scheiner, A.P. (1982). A review and analysis of the effectiveness of early intervention programs. Pediatrics, 69, 635-651.

Smith, D., Deshler, D., Hallahan, D., Lovitt, T., Robinson, S., Voress, J., \& Ysseldyke, J. (1984). Minimum standards for the description of subjects in learning disabilities research reports. Learning Disability Quarterly, 7, 221-224.

Smith, D.D., \& Luckasson, R. (1992). Introduction to special education: Teaching in an age of challenge. Boston: Allyn \& Bacon.

Spitz, H.H. (1986). The raising of intelligence: A selected history of attempts to raise retarded intelligence. Hillsdale, $\mathrm{NJ}$ : Erlbaum.

Stainback, W., \& Stainback, S. (1984). A rationale for the merger of special and regular education. Exceptional Children, 51, 102-111.

Strain, P.S. (1990). LRE for preschool children with handicaps: What we know, what we should be doing. Journal of Early Intervention, 14, 291-296.

Strickland, B., \& Turnbull, A. (1990). Developing and implementing individualized educational programs. Columbus, $\mathrm{OH}$ : Merrill.

Sutherland, J., \& Algozzine, R. (1979). The LD label as a biasing factor in the visual motor performance of normal children. Journal of Learning Disabilities, 16, $320-321$.

Taylor, S. (1988). Caught in the continuum: A critical analysis of the principle of the least restrictive environment. Journal of the Association for Persons with Severe Handicaps, 13(1), 41-53.

Thousand, J.S., \& Villa, R.A. (1990). Strategies for educating learners with severe disabilities within their local home schools and communities. Focus on Exceptional Children, 23(3), 1-24.

Tjossem, T.D. (1976). Intervention strategies for high-risk infants and young children. Baltimore: University Park Press.

U.S. Department of Education. (1990). To assure the free appropriate public education of all handicapped children: Twelfth annual report to Congress on the implementation of The Education of the Handicapped Act. Washington, DC: Office of Special Education Programs. 
Wallach, G.P., \& Butler, K.G. (1984). Language learning disabilities in school-age children. Baltimore: Williams \& Wilkins.

Wang, M., \& Walberg, H.J. (1988). Four fallacies of segregationism. Exceptional Children, 55, 138-146.

Warner, M.M., Schumaker, J.B., Alley, G.B., \& Deshler, D.D. (1980). Learning disabled adolescents in the public schools: Are they different from other low achievers? Exceptional Education Quarterly, 1, 27-36.

Westlake, C.R., \& Kaiser, A.P. (1991). Early childhood services for children with severe handicaps: Research, values, policy and practice. In L.H. Meyer, C.A. Peck, \& L. Brown (Eds.), Critical issues in the lives of persons with severe disabilities (pp. 429-458). Baltimore: Brooks.

White, K., Bush, D., \& Casto, G. (1985). Learning from previous reviews of early intervention research. The Journal of Special Education, 19, 417-428.

White, K.R., Toohill, M., \& Haring, K.A. (1991). Results of a randomized trial of home-based early intervention for children with disabilities. Manuscript submitted for publication.

Wolery, M. (1991). Instruction in early childhood special education: "Seeing through a glass darkly . . . Knowing in part." Exceptional Children, 58, 127-135.

Ysseldyke, J.E., \& Algozzine, B. (1981). Diagnostic classification decisions as a function of referral information. The Journal of Special Education, 15, 429-435.

Ysseldyke, J.E., \& Algozzine, B. (1983). LD or not LD: That's not the question. Journal of Learning Disabilities, 16, 29-31.

Ysseldyke, J.E., \& Algozzine, B. (1984). Introduction to special education. Boston: Houghton Mifflin.

Ysseldyke, J.E., \& Algozzine, B. (1990). Introduction to special education (2nd ed.). Boston: Houghton Mifflin.

Ysseldyke, J.E., Algozzine, B., \& Epps, S. (1983). A logical and empirical analysis of current practices in classifying students as handicapped. Exceptional Children, 50, 160-166.

Ysseldyke, J.E., Algozzine, B., \& Richey, L. (1982). Judgement under uncertainty: How many children are handicapped? Exceptional Children, 48, 531-534.

Ysseldyke, J.E., Algozzine, B., Richey, L., \& Graden, J. (1982). Declaring students eligible for learning disabilities services: Why bother with the data? Learning Disability Quarterly, 5, 37-44.

Ysseldyke, J.E., Algozzine, B., Shinn, M.R., \& McGue, M. (1982). Similarities and differences between low achievers and students classified as learning disabled. The Journal of Special Education, 16, 73-85.

Ysseldyke, J.E., Algozzine, B., \& Thurlow, M.L. (1992). Critical issues in special education (2nd ed.). Boston: Houghton Mifflin. 